\title{
Start-up of upward conveyor based on AMT
}

\author{
Yunxia $\mathrm{LI}^{\mathrm{a}}{ }^{*}$, Zengcai WANG ${ }^{\mathrm{b}}$ and Weili PENG ${ }^{\mathrm{c}}$ \\ School of Mechanical Engineering, Shandong University, China

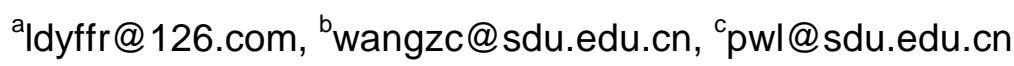

Keywords: automated mechanical transmission; upward conveyor; start-up; simulation

Abstract. AMT (Automated Mechanical Transmission) has been used in heavy-duty trucks for its high efficiency, low cost and high torque. In this paper, AMT is used as a soft-starting device to start up upward conveyors softly. On the basis of dynamic characteristics, clutch torque control strategy is put forward to control start-up process in upward conveyors. Simulation research is given based on three-phase induction motor. Simulation results prove that the start-up control strategy is effective. The belt acceleration and the belt jerk can be controlled within a certain limit.

\section{Introduction}

So far, most of soft-starting devices for belt conveyors are variable frequency speed regulating, fluid coupling, AC motor soft starter, and liquid viscous speed regulating differential frequency speed regulating. These soft-starting devices are mostly prices higher, and restricted by external condition, such as high-voltage power supply [1-4]. AMT is being used in vehicles because of the advantages of low cost and higher efficiency [5,6]. This paper provides AMT as the soft-starting device on belt conveyors. For the reason of high running resistance on upward conveyors, the start-up process becomes the key problem on AMT driving upward conveyors.

\section{Kinetic analysis of upward conveyor}

As is shown in figure 1 , force analysis of upward conveyor can be indicated. $F_{p}$ is tensioning force at the tensioning drum, $F_{t}$ is driving force at the driving drum, and $F_{f}$ is running resistance.

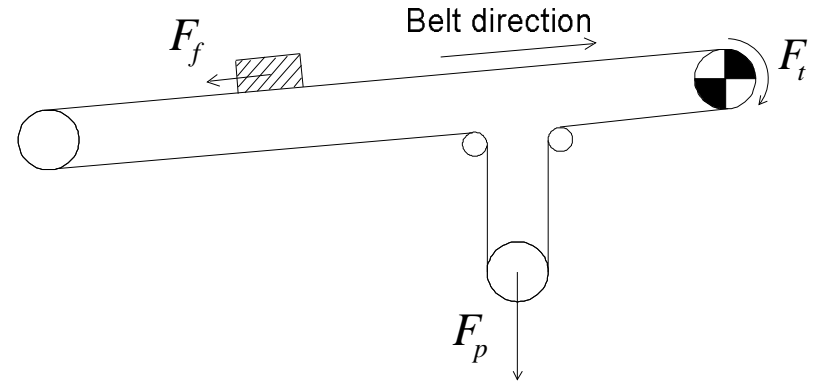

Fig. 1 Force schematic diagram of upward conveyor Belt conveyor's motion equation is expressed in equation 1.

$F_{t}-F_{f}-F_{a}=0$

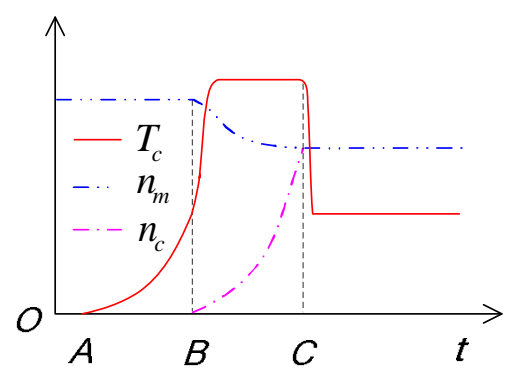

Fig. 2 Ideal clutch engaging process

Acceleration resistance of the upward conveyor can be expressed in equation 2 .

$F_{a}=m a$

Where $F_{a}$ is acceleration resistance, $a$ is belt acceleration, $m$ is equivalent mass of load.

Driving force derives from clutch control torque according to power transmission. Driving force can be expressed in equation 3.

$$
F_{t}=\frac{T_{c} i_{g} i_{0} \eta}{R}
$$

Where $T_{c}$ is clutch controlling torque, $\eta$ is mechanical efficiency of power train, $R$ is radius of driving pulley, $i_{g}$ and $i_{0}$ are transmission ratio and reducer ratio respectively. 
The running resistance can be consisted of several forces in equation 4.

$F_{f}=F_{H}+F_{N}+F_{S t}+F_{S}$

Where $F_{H}$ is primary resistance, $F_{N}$ is additional resistance, $F_{S t}$ is hoist resistance, and $F_{S}$ is special kind of resistance.

The hoist resistance can be expressed in equation 5 .

$F_{S t}=m_{G} g \sin \theta$

Where $m_{G}$ is loading mass, $g$ and $\theta$ are gravitational acceleration and conveyor angle separately.

The primary resistance and the additional resistance can be expressed as follows.

$F_{H}+F_{N}=C f L g\left(q_{R o}+q_{R U}+2 q_{B} \cos \theta\right)+C f m_{G} g \cos \theta$

Where $C$ is resistance coefficient, $f$ is frictional coefficient between belt and goods, $q_{R O}$ is upper roller mass per unit length, $q_{R U}$ is lower roller mass per unit length, $q_{B}$ and $q_{G}$ are belt mass per unit length and goods mass per unit length respectively.

It can be seen that the running resistance is a function of slope angle and goods mass from equation 4 to equation 6 . To be sure, the bigger the slope angle, the bigger the running resistance.

\section{Analysis of clutch torque during start-up process}

Based on power source of three-phase induction, the power train comprises AMT, reducer and driving pulley. Clutch is the power device which can combine and cut power transmission. So, it is necessary to analysis the clutch controlling torque.

The clutch fractional torque is decided as equation 7 .

$$
T_{c}=u z F_{c} R_{e}=\frac{1}{3} \mu z F_{c} \frac{D^{3}-d^{3}}{D^{2}-d^{2}}
$$

Where $u$ is fractional coefficient, $z$ is the number of fractional surface, $F_{c}$ is work force at large end of diaphragm spring, $R_{e}$ is effective radius of diaphragm spring, $D$ and $d$ are inner and outer diameter of diaphragm spring separately.

The work force at large end of diaphragm spring is connected with the deformation at small end of diaphragm spring which is related to the displacement of clutch release bearing. The displacement of clutch release bearing is concerned in the displacement of clutch power cylinder because they are related via release fork. That is, the two displacements have a lever ratio relation.

To simplify the analysis, there is a linear relationship between the clutch torque and the displacement of clutch power cylinder which is expressed in equation 8 if the temperature and the wearing of friction discs are ignored.

$$
T_{c}=T\left(\mu, z, s, R_{e}\right)
$$

Where $s$ is the displacement of clutch power cylinder.

The engaging process of clutch can be divided into four stages. The first stage is eliminating free gap from none moment to A moment. The second stage is overcoming resistance from A moment to B moment. The third stage is accelerating load from $\mathrm{B}$ to $\mathrm{C}$ moment. The fourth stage is uniform motion from $\mathrm{C}$ moment. During the ideal clutch engaging process, the motor speed, the clutch torque and the speed of clutch friction disc can be illustrated in figure 2 .

The first stage should be faster because of no torque transmission. The second stage should be slower in order to start-up softly. The third stage should be faster for the sake of reducing the acceleration time and reaching the target displacement of clutch power cylinder earlier. The fourth stage should be fastest that the clutch moves to its full engagement position.

To meet the needs of limit in belt acceleration, the clutch controlling torque can be expressed in equation 9 .

$$
T_{c}=\frac{m a R+T_{e}}{i_{g} i_{0} \eta}<\frac{m a_{\max } R+T_{e}}{i_{g} i_{0} \eta}
$$


Where $a_{\max }$ is the value of belt maximum acceleration.

The belt maximum tension should be limited in equation 10 .

$F_{b \max } \leq 1.8 F_{b N}$

Where $F_{b \max }$ and $F_{b N}$ are belt maximum tension and belt rated tension.

\section{Simulation analysis}

Main parameters are stated as follows. Rated power and rated speed of the three-phase induction motor are 110 kilowatt and $1480 \mathrm{r} / \mathrm{min}$ separately. The previous three gear ratios of transmission are 14.28, 10.62 and 7.87 orderly. The gear ratio of reducer is 10 . The belt is one hundred meters in length. The slope angle is fifteen degree. The belt specification is ST-1250 with a belt width of 1200 millimeters and the mass per unit time of 800 thousand kilograms per hour. The modulus of elasticity is $1250 \mathrm{~N} / \mathrm{mm}$. There are mainly six pulleys on the conveyor. Diameter and moment of inertia for driving pulley are 1 meter and $262 \mathrm{~kg} \cdot \mathrm{m}^{2}$ separately. The tail pulley and the tensioning pulley are identical which diameter and moment of inertia are 800 millimeters and $87 \mathrm{~kg} \cdot \mathrm{m}^{2}$ separately. Diameter and moment of inertia for the two bend pulleys are 630 millimeters and 38 $\mathrm{kg} \cdot \mathrm{m}^{2}$ separately. Their surrounding angle is 90 degrees. The diameter and grove angle of rollers are 133 millimeters and 35 degrees separately. The spaces of upper rollers and under rollers are 1.2 meters and 3 meters separately. There are twenty meters between the tensioning pulley and the driving pulley.
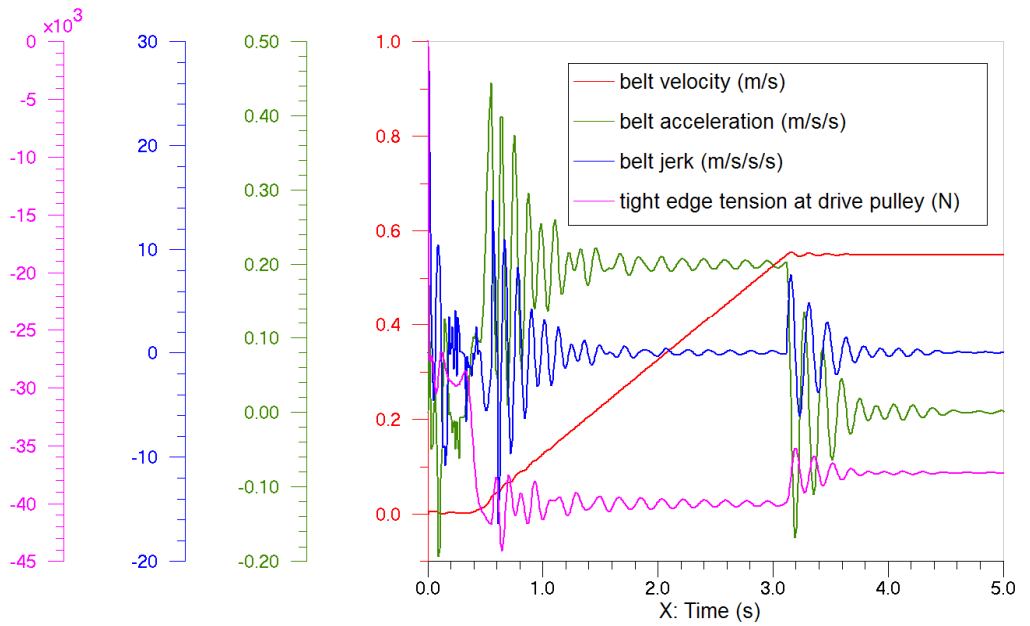

Fig. 3 Start-up process under first gear position
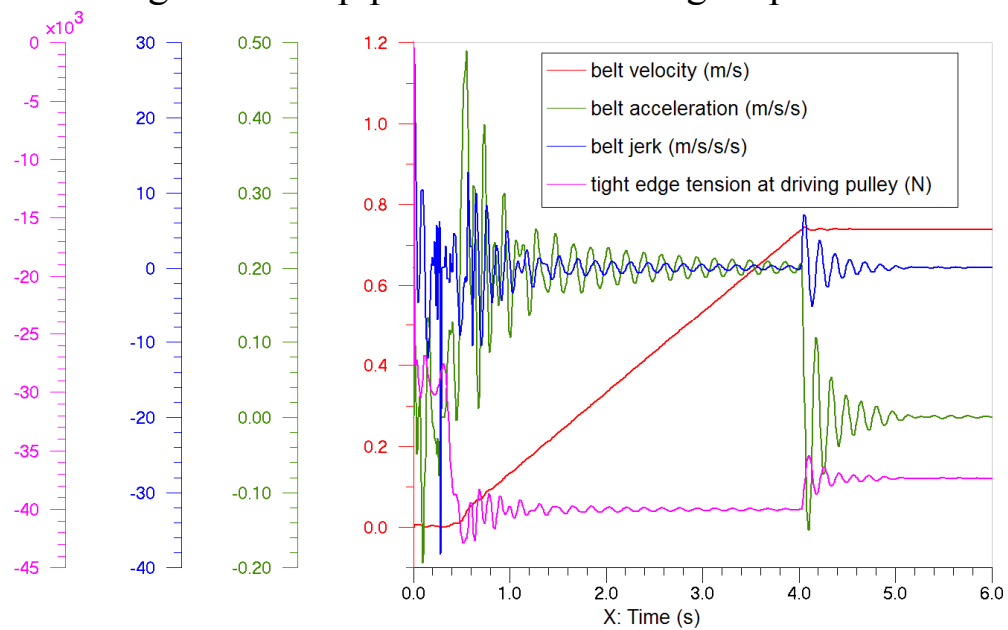

Fig. 4 Start-up process under second gear position 

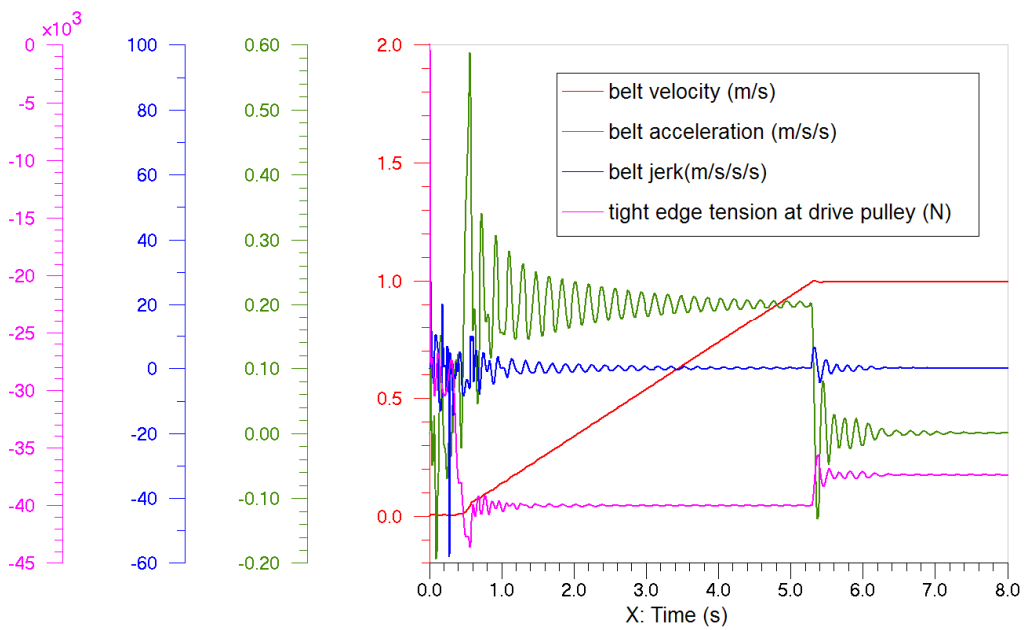

Fig. 5 Start-up process under third gear position

The simulation analysis of start-up process is given under three gear positions. Separately, under conditions of first gear position, second gear position and third gear position, the belt velocity, the belt acceleration, the belt jerk, the tight edge tension at driving pulley are shown in three figures above.

As can be seen from figure 3, figure 4 and figure 5, the parameters can be controlled by controlling clutch engagement during start-up process. Of course, with the rising of gear position, belt jerk changes bigger. The value of tight edge tension at driving pulley is lower than the allowable longitudinal tension limit of $1500 \mathrm{KN}$.

\section{Conclusion}

All as in conclusion, the paper gives a method of AMT driving upward conveyor. On the basis of force analyzing of upward conveyor, the relationship between the belt acceleration and the slope angle is established. The strategy of clutch controlling torque is proposed for AMT starting up upward conveyor. Simulation results show that the method of AMT starting up upward conveyor is effective. Belt jerk under three gear positions is within the limit of belt longitudinal tension.

\section{References}

[1] W. G. Song, H. Y. Liu, Y. Wang, Research on Dynamic and Computer Simulation of the Belt Conveyor, J. Chinese Journal of Mechanical Engineering. 39 (2003) 133-138.

[2] L. K. Nordell, The channer $20 \mathrm{~km}$ overland-a flagship of modern belt conveyor technology, J. Bulk Solids Handling. 11 (1991) 781-792.

[3] G. B. Wang, Study on belt conveyor controlled start transmission equipment, J. Journal of China Coal Society. 28 (2003) 316-312.

[4] W. G. Song, D. Wang, B. Zuo, Semi-analytical solution to dynamic continuous model of belt conveyor with single drive, J. Journal of China Coal Society. 37 (2012) 217-223.

[5] L. Glielmo, L. Iannelli, V. Vacca, et al. Gearshift control for automated manual transmission, J. IEEE/ASME Transactions on Mechatronics. 11 (2006) 17-26.

[6] G. Lucente, M. Montanari, C. Rossi. Modelling of an automated manual transmission system, J. Mechatronics. 17 (2007) 73-91. 